\title{
Angulation of the ossified stylohyoid complex and Eagle syndrome
}

\author{
Fatma Caylakli ${ }^{1} \mathbb{D}$ \\ Received: 7 September 2018 / Accepted: 15 September 2018 / Published online: 21 September 2018 \\ c) Springer-Verlag GmbH Germany, part of Springer Nature 2018
}

Dear Sir,

I read the manuscript entitled "Length of the ossified stylohyoid complex and Eagle syndrome" by Ledesma-Montes et al. [1]. The manuscript is so much valuable, especially because of explaining the stylohyoid complex (SHC) terminology. It is also so much valuable to investigate the correlation between the length of ossified portion of SHC (OPSHC) and signs and symptoms of Eagle's syndrome. I just want to declare some points that limit the power of this study. The measurements of OPSHC were made on panoramic radiographs. There is no picture of panoramic radiograph in the manuscript. It would be better to use a panoramic radiograph and to show the anatomical components of the SHC on panoramic radiograph. It would be easier for the readers to see and understand the anatomical details of this complex on radiograph. The other subject is about correlation between SHC and signs and symptoms of Eagle's syndrome. OPSHC can project into the tonsillar fossa or impinge upon vital structures in the neck and pharynx to cause various neurological or vascular symptoms. Abnormal angulation and the distance to the tonsillar fossa rather than elongation of the OPSHC may be responsible for the irritation of a number of structures coursing through the parapharyngeal space [2-4]. Panoramic radiograph limits the measurement of anterior-posterior angle (sagittal plane angle) which is an important factor for the sign and symptoms of Eagle's syndrome. And also the distance of OPSHC to the tonsillar fossa cannot be measured correctly on a panoramic radiograph.

\section{Compliance with ethical standards}

Conflict of interest The authors declare no conflict of interest whatsoever arising out of the publication of this manuscript.

\section{References}

1. Ledesma-Montes C, Hernández-Guerrero JC, Jiménez-Farfán MD (2018) Length of the ossified stylohyoid complex and Eagle syndrome. Eur Arch Otorhinolaryngol 275(8):2095-2100

2. Yavuz H, Caylakli F, Yildirim T, Ozluoglu LN (2008) Angulation of the styloid process in Eagle's syndrome. Eur Arch Otorhinolaryngol 265(11):1393-1396

3. Burulday V, Akgül MH, Bayar Muluk N, Yağdiran B, Inal M (2017) The importance of medial-lateral styloid process angulation/coronal plane angle in symptomatic eagle syndrome. Clin Anat 30(4):487-491

4. Kent DT, Rath TJ, Snyderman C (2015) Conventional and 3-dimensional computerized tomography in Eagle's syndrome, glossopharyngeal neuralgia, and asymptomatic controls. Otolaryngol Head Neck Surg 153(1):41-47

This comment refers to the article available online at https://doi. org/10.1007/s00405-018-5031-3.

Fatma Caylakli

fcaylakli@yahoo.com

1 Otorhinolaryngology Head and Neck Surgery Department, Baskent University School of Medicine, Ankara, Turkey 